\title{
EGU21-8280
}

https://doi.org/10.5194/egusphere-egu21-8280

EGU General Assembly 2021

(c) Author(s) 2021. This work is distributed under

the Creative Commons Attribution 4.0 License.

\section{Potential field constraints on the basement structure of the Taiwan thrust-and-fold belt: preliminary results}

\author{
Olivia Lozano ${ }^{1,2}$, Puy Ayarza ${ }^{2}$, Joaquina Alvarez-Marrón ${ }^{1}$, and Dennis Brown ${ }^{1}$ \\ ${ }^{1}$ Geosciences Barcelona, GEO3BCN - CSIC, Lluis Sole i Sabaris s/n, 08028, Barcelona, Spain (olozano@geo3bcn.csic.es) \\ ${ }^{2}$ Department of Geology, University of Salamanca, Plaza de la Merced s/n, 37008, Salamanca, Spain
}

The Taiwan orogen forms an active mountain range that has been evolving since the Late Miocene as a result of the oblique collision between the Luzon Arc, located in the Philippine Sea Plate, and the continental margin of the Eurasian Plate. Due to this configuration, some inherited structures from the continental margin are at high angle to the structural trend of the Taiwan thrust-and-fold belt and are thought to play an important role in present day tectonics. The inherited structures resulted from processes undergone by the Eurasian margin, such as rifting in the Early Eocene, and further local extension in the Middle Miocene. They comprise sub-vertical faults that are presently being reactivated and are actively involved in the evolution of the structure, seismicity and topography of Taiwan, causing transverse zones in its thrust-and-fold belt and foreland.

The key objective of this research is to help define the deep structure in southern Taiwan, as well as the location and kinematics of these inherited east-northeast striking faults. To achieve this goal, we undergo a multidisciplinary approach based on the analysis and modelling of gravity (freeair and Bouguer anomaly) and magnetic data. The application of analytical techniques, such as horizontal directional derivatives allows us to identify gradients that can be related to the geometry and minimum horizontal extent of these basement structures in the margin and in Taiwan. Forward modelling of gravity and magnetic data contributes further to provide a betterconstrained quantitative approach to their depth as they appear to affect the top of the basement. Finally, these results have been integrated with structural studies and earthquake information in order to improve our understanding of the southern Taiwan and Eurasian continental margin structure.

The preliminary results allow us to discuss the limitations of vertical derivatives and residual potential field data when dealing with deep inherited basement structures. The present dataset has proven to be useful to discern the existence of a deformed reactivated basement in the foreland and frontal part of the Taiwan thrust-and-fold belt, and improve our comprehension of its crustal structure. Due to the limitations of potential field data as the depth of the source increases, the resolution diminishes towards the $\mathrm{E}$ of the thrust-and-fold belt.

This research is part of project PGC2018-094227-B-100 funded by the Spanish Research Agency of the Ministry of Science and Innovation of Spain. Olivia Lozano acknowledges funding from the same agency through contract PRE2019-091431. 
